\title{
Age-Related Resistance in Arabidopsis thaliana Involves the MADS-Domain Transcription Factor SHORT VEGETATIVE PHASE and Direct Action of Salicylic Acid on Pseudomonas syringae
}

\author{
Daniel C. Wilson, ${ }^{1}$ Christine J. Kempthorne, ${ }^{1}$ Philip Carella, ${ }^{1}$ David K. Liscombe, ${ }^{2}$ and \\ Robin K. Cameron ${ }^{1,+}$ \\ ${ }^{1}$ McMaster University, 1280 Main Street West, Hamilton, Ontario, L8S 4K1, Canada; and ${ }^{2}$ Vineland Research and Innovation \\ Centre, 4890 Victoria Avenue N., Vineland Station, Ontario, LOR 2E0, Canada
}

Accepted 14 August 2017.

\begin{abstract}
Arabidopsis thaliana exhibits a developmentally regulated disease-resistance response known as age-related resistance (ARR), a process that requires intercellular accumulation of salicylic acid (SA), which is thought to act as an antimicrobial agent. ARR is characterized by enhanced resistance to some pathogens at the late adult-vegetative and reproductive stages. While the transition to flowering does not cause the onset of ARR, both processes involve the MADS-domain transcription factor SHORT VEGETATIVE PHASE (SVP). In this study, ARR-defective svp mutants were found to accumulate reduced levels of intercellular SA compared with wild type in response to Pseudomonas syringae pv. tomato. Double mutant and overexpression analyses suggest that SVP and SOC1 (SUPPRESSOR OF OVEREXPRESSION OF CO 1) act antagonistically, such that SVP is required for ARR to alleviate the negative effects of SOC1 on SA accumulation. In vitro, SA exhibited antibacterial and antibiofilm activity at concentrations similar to those measured in the intercellular space during ARR. In vivo, $P$. syringae pv. tomato formed biofilm-like aggregates in young susceptible plants, while this was drastically reduced in mature ARR-competent plants, which accumulate intercellular SA. Collectively, these results reveal a novel role for the floral regulators SVP and SOC1 in disease resistance and provide evidence that $\mathrm{SA}$ acts directly on pathogens as an antimicrobial agent.
\end{abstract}

Many plants exhibit enhanced resistance to disease at later developmental stages (Develey-Rivière and Galiana 2007; Whalen 2005). This phenomenon is often referred to as agerelated resistance (ARR). The model plant Arabidopsis thaliana displays ARR to Pseudomonas syringae, resulting in reduced bacterial growth in the leaf intercellular space of mature plants compared with young plants (Kus et al. 2002). ARR is a

Current address for Philip Carella: Sainsbury Laboratory, University of Cambridge, Bateman Street, Cambridge, United Kingdom, CB2 1LR

${ }^{\dagger}$ Corresponding author: Robin K. Cameron; E-mail: rcamero@mcmaster.ca

*The $\boldsymbol{e}$-Xtra logo stands for "electronic extra" and indicates that 11 supplementary figures and one supplementary table are published online.

(c) (i) $(9)$ Copyright $(92017$ The Author(s). This is an open access article distributed under the CC BY-NC-ND 4.0 International license. salicylic acid (SA)-dependent process, as several SA-deficient mutants are ARR-defective (Cameron and Zaton 2004; Carviel et al. 2009; Kus et al. 2002). However, SA signaling mutants are ARR-competent, suggesting that SA-mediated defense signaling is not essential for ARR (Carella et al. 2015; Kus et al. 2002). Instead, it is thought that SA acts directly on the pathogen as an antimicrobial agent during ARR. Evidence supporting this hypothesis includes the observation that antibacterial activity and SA are both detected in intercellular washing fluids (IWFs) of mature plants after inoculation with $P$. syringae pv. tomato DC3000 but not in IWFs of untreated or young plants inoculated with $P$. syringae pv. tomato (Cameron and Zaton 2004; Kus et al. 2002). Moreover, addition of SA to the intercellular space of SA-deficient mutants restores ARR and reduction of intercellular SA levels in wild-type plants by pressure-infiltrating with SA hydroxylase compromises ARR (Cameron and Zaton 2004). Finally, SA exhibits antimicrobial activity against a variety of phytopathogens in vitro (Amborabé et al. 2002; Brown et al. 2007; Cameron and Zaton 2004; El-Mougy 2002; Georgiou et al. 2000; Martín et al. 2010; Prithiviraj et al. 1997; Lowe-Power et al. 2016; Yuan et al. 2007); however, concentrations greater than $1 \mathrm{mM}$ are often required and it is unclear whether these concentrations are reached in planta.

ARR coincides with the transition to flowering in both shortday (9 h of light) and long-day (16 h of light) photoperiods (Rusterucci et al. 2005). Despite the co-occurrence of these developmental events, analysis of flowering-time mutants and wild-type plants that were induced to flower early by transient exposure to long days demonstrated that the transition to flowering is neither sufficient nor required for the onset of ARR (Wilson et al. 2013). Interestingly, the same study also revealed that SVP (SHORT VEGETATIVE PHASE) plays a role in both processes, since mutants for this well-known flowering-time regulator were found to be ARR-defective.

The transition to flowering is a highly regulated process affected by numerous environmental and endogenous signals (Amasino 2010; Fornara et al. 2010). A few key genes act to integrate these signals, including $S V P$, a major negative regulator of flowering (Hartmann et al. 2000). SVP is a MADS-domain transcription factor that delays flowering, in the absence of inductive signals, through direct repression of positive regulators of flowering such as SOC1 (SUPPRESSOR OF OVEREXPRESSION OF CO 1) (Gregis et al. 2013; Li et al. 2008). SOC1 functions primarily at the shoot apical meristem, in which it activates the floral meristem identity gene $L F Y$ ( $L E A F Y)$ to initiate 
flowering in response to inductive signals such as long days, gibberellic acid, and aging (Lee et al. 2008; Liu et al. 2008; Moon et al. 2005). SVP also represses SOCl in leaves ( $\mathrm{Li}$ et al. 2008); however, the biological significance of this interaction is unclear.

In this study, investigation of the role of SVP during ARR revealed that SVP is required for intercellular SA accumulation and identified SOC1 as an additional MADS-domain transcription factor that affects both flowering and ARR. The potential for direct action of SA on $P$. syringae pv. tomato was assessed by antibacterial and biofilm assays in minimal medium that reflects the conditions in the intercellular space. Low concentrations of SA ( $\geq 2 \mu \mathrm{M})$ reduced biofilm formation, while higher concentrations $(\geq 100 \mu \mathrm{M})$ reduced bacterial growth. Moreover, accumulation of SA in the intercellular space during ARR was associated with reduced formation of biofilm-like aggregates of $P$. syringae pv. tomato, suggesting that intercellular SA directly impacts either pathogen growth, biofilm formation, or both in mature Arabidopsis.

\section{RESULTS}

\section{SA accumulation is reduced}

in $s v p$ mutants responding to $P$. syringae.

We first became interested in SVP upon discovering that mutants for this gene were ARR-defective (Wilson et al. 2013) (Fig. 1A). Given that SA accumulation is a key component of the ARR response, we hypothesized that SVP might regulate SA accumulation, in which case svp mutants should be compromised in their ability to accumulate SA. Therefore, SA was measured in mature Col- 0 and $s v p-41$ before and after inoculation with $P$. syringae pv. tomato. Specifically, SA levels were measured in IWFs and leaf tissue (with IWFs removed) to assess intercellular and intracellular fractions of SA, respectively. As expected, Col-0 accumulated intracellular free SA and intracellular glucose-conjugated SA (SAG) in response to $P$. syringae pv. tomato (Fig. 1C and D). The svp-41 mutant also accumulated intracellular free SA, albeit with a small but statistically significant 1.2-fold reduction, relative to Col-0, at $24 \mathrm{~h}$ postinoculation (hpi). Intracellular SAG accumulation was noticeably reduced in $s v p-41$ relative to Col-0 at 24 and $48 \mathrm{hpi}$ (two- to fourfold reduction). While little to no intercellular SAG accumulates in response to $P$. syringae pv. tomato (Carviel et al. 2014), free SA accumulated to $2,093 \mathrm{ng} \mathrm{ml}^{-1}$ in Col-0 IWFs at $24 \mathrm{hpi}$ but was reduced to $711 \mathrm{ng} \mathrm{ml}^{-1}$ in svp-41 (threefold reduction) (Fig. 1B). These data suggest that SVP function contributes to intracellular and intercellular SA accumulation during ARR.

\section{Addition of SA to the intercellular space restores ARR to svp mutants.}

If the ARR-defective phenotype of $s v p$ mutants is caused by reduced intercellular SA accumulation, then adding exogenous SA to the intercellular space should restore ARR in svp mutants. To test this, $0.1 \mathrm{mM} \mathrm{SA}$ or a mock solution was pressureinfiltrated into the leaves of mature plants either 4 or $24 \mathrm{~h}$ before inoculation with $P$. syringae pv. tomato. Bacterial levels were then measured at 3 days postinoculation (dpi). Col-0 served as a positive control for ARR, and the SA-deficient sid2-2 mutant was included as a negative control for ARR and because application of exogenous SA restores ARR to sid 2 mutants (Cameron and Zaton 2004). Mock-treated svp-32 and sid2-2 supported higher bacterial levels than Col-0, consistent with the ARR-defective phenotypes of both mutants (Fig. 2). When SA was applied $4 \mathrm{~h}$ before inoculation with $P$. syringae pv. tomato, svp-32 and sid2-2
A
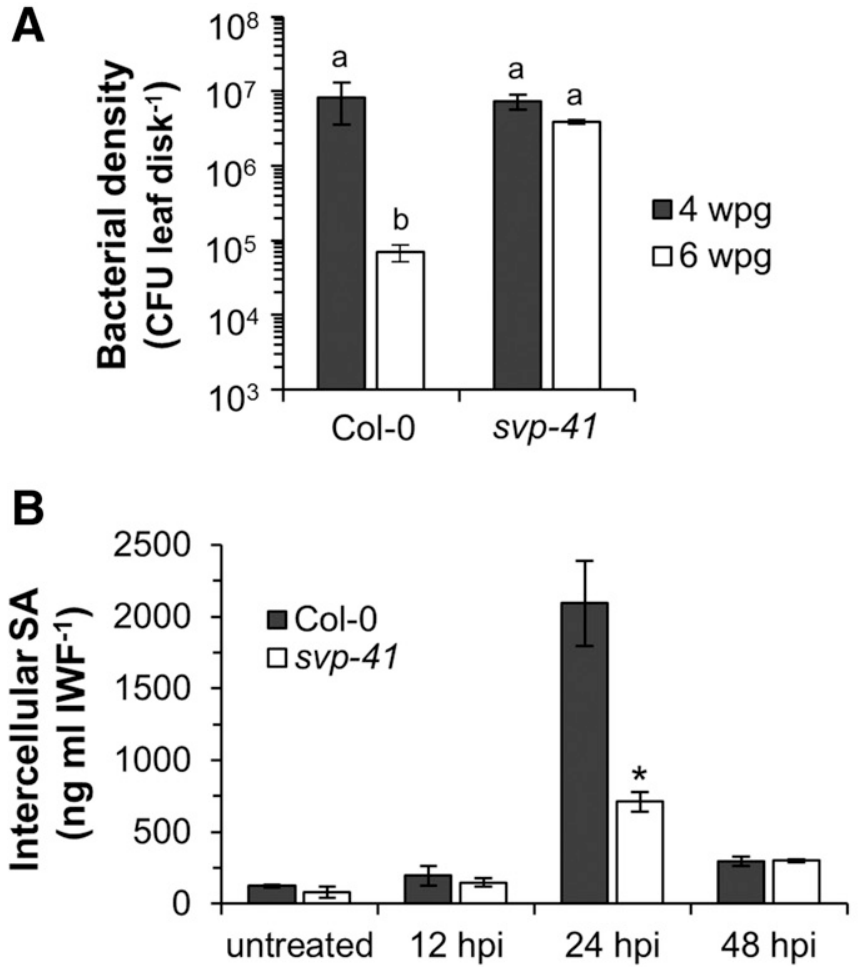
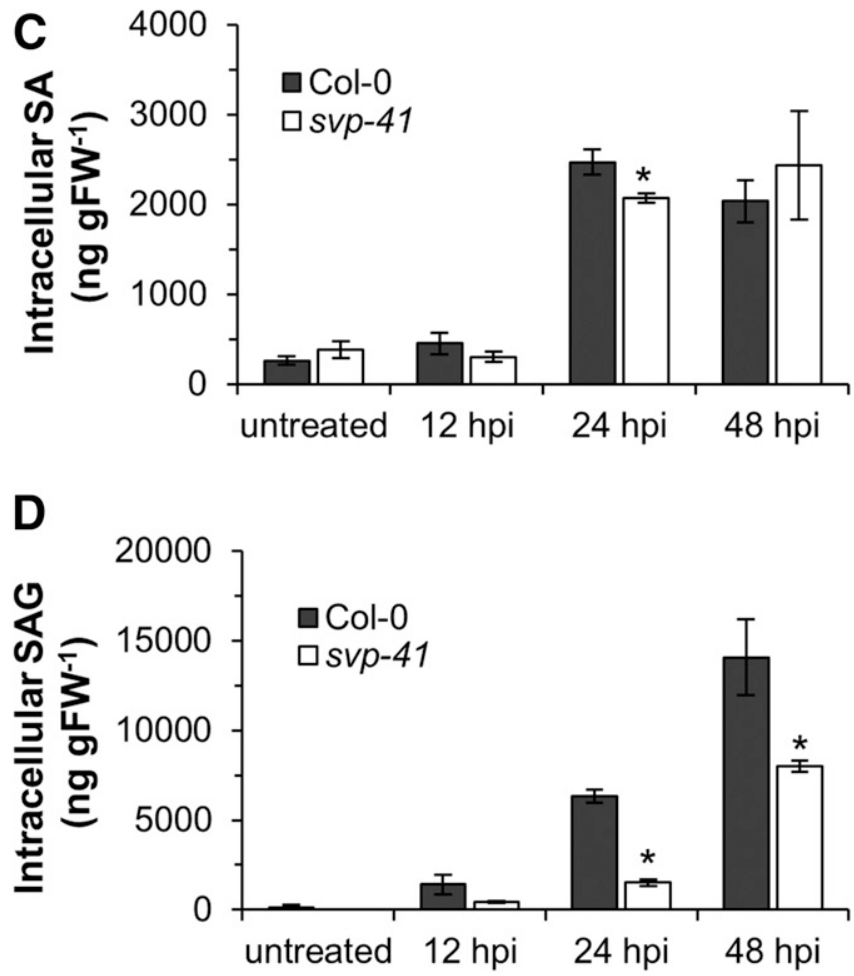

Fig. 1. Age-related resistance-defective svp-41 mutants have reduced salicylic acid (SA) accumulation in response to Pseudomonas syringae. A, Plants were inoculated with $10^{6} \mathrm{CFU} \mathrm{ml^{-1 }}$ P. syringae pv. tomato at either 4 or 6 weeks postgermination (wpg) and bacterial levels were quantified 3 days later. Different letters indicate significant differences (analysis of variance followed by Tukey's honestly significant difference test, $P<0.05$ ). B, SA was measured in intercellular washing fluids (IWFs) collected from plants that were either untreated or inoculated with $10^{6} \mathrm{CFU} \mathrm{ml}^{-1} P$. syringae pv. tomato. C, SA and $\mathbf{D}$, SA glucosides (SAG) were measured in the corresponding leaves (from which IWFs had been removed). Asterisks indicate significant differences between genotypes at the same timepoint $(t$ test, $P<0.05)$. Each bar shows the mean of three sample replicates and error bars show standard deviation. These experiments were performed three times with similar results. 
both supported lower bacterial levels relative to their mocktreated counterparts, whereas resistance was not enhanced in ARR-competent Col-0, as observed previously (Cameron and Zaton 2004). In contrast, when SA was applied $24 \mathrm{~h}$ before inoculation with $P$. syringae pv. tomato, all three genotypes supported similar bacterial levels relative to their mock-treated counterparts. Similar results were observed with the svp-41 mutant (Supplementary Fig. S1). Previous work has shown that leaves pressure-infiltrated with $0.1 \mathrm{mM}$ SA contain elevated SA in IWFs after $5 \mathrm{~h}$, with a return to untreated levels after $24 \mathrm{~h}$ (Cameron and Zaton 2004). Together, these data suggest that exogenous intercellular SA restores ARR in svp mutants. These data link the ARR-defective phenotype of $s v p$ mutants to reduced intercellular SA accumulation and further demonstrate the importance of intercellular SA for ARR.

\section{Direct action of SA on $P$. syringae.}

In rich medium (King's B $[\mathrm{KB}]$ ), $P$. syringae pv. tomato growth is reduced at $\mathrm{SA}$ concentrations of $\geq 1 \mathrm{mM}$ (Cameron and Zaton 2004) and $\geq 2 \mathrm{mM}$ (Fig. 3A). Since characteristics of the growth medium (e.g., $\mathrm{pH}$ ) can influence bacterial growth rate, metabolism, and physiology (Kim et al. 2010), as well as the activity of antimicrobial agents (Amborabé et al. 2002), the antibacterial activity of SA was assessed in conditions similar to those found in the leaf intercellular space. To accomplish this, antibacterial assays were conducted using hrp-inducing minimal (HIM) medium (Huynh et al. 1989), which more closely resembles the composition of the leaf intercellular space. In HIM medium, the growth of $P$. syringae pv. tomato was reduced at 100 to $200 \mu \mathrm{M} \mathrm{SA}$ and was completely inhibited at $1 \mathrm{mM}$ (Fig. 3B). At $\geq 2 \mathrm{mM} \mathrm{SA}$, no colonies were observed when the culture was transferred to solid KB medium without SA, suggesting that SA had bactericidal activity (Supplementary Fig. S2). Therefore, SA is a stronger antibacterial agent under conditions that better represent the intercellular space. It has been suggested that acidification of the culture medium by SA accounts for its toxic effects (Van Duy et al. 2007); however, in our experiments, SA had little effect on $\mathrm{pH}$ at the concentrations tested (Supplementary Fig. S3). Since some plant pathogens degrade SA and use it as a carbon source (Lowe-Power et al. 2016; Rabe et al. 2013), we speculated that $P$. syringae pv. tomato may also have this ability. However, P. syringae pv. tomato was unable to grow in HIM medium with SA as the sole carbon source, suggesting that $P$. syringae pv. tomato DC3000 lacks the ability to degrade SA (Supplementary Fig. S4).

Several studies suggest that biofilm formation contributes to the virulence of $P$. syringae on various hosts, including Arabidopsis (Aslam et al. 2008; Schenk et al. 2008; Yu et al. 1999). This led us to speculate that elevated intercellular SA levels during ARR may reduce $P$. syringae pv. tomato biofilm formation; therefore, we examined whether treatment with SA reduces $P$. syringae pv. tomato biofilm formation in vitro. The ability of $P$. syringae pv. tomato to form biofilms in vitro was assessed using a spectrophotometric microplate assay, in which staining of surface-adherent cells with crystal violet allows for quantification of biofilm formation (O'Toole 2011). In KB medium, $P$. syringae pv. tomato biofilm formation was negligible (Supplementary Fig. S5), whereas extensive biofilm formation was observed beginning at $24 \mathrm{~h}$ in HIM medium (Fig. 4A). Interestingly, biofilm formation was reduced by SA in a concentration-dependent manner, as shown by quantitative assays (Fig. 4A) and qualitative assays performed with test tubes instead of microplates (Fig. 4B). The effect was most dramatic at $24 \mathrm{~h}$ and onwards, once extensive biofilm formation had occurred in the SA-free controls. At the lowest effective concentrations of SA (2 to $5 \mu \mathrm{M})$, biofilm formation was reduced by 1.3 - to 2.3-fold. At higher concentrations (50 to $100 \mu \mathrm{M})$, similar to the levels estimated to accumulate in the intercellular space during ARR (Fig. 1C), biofilm formation was reduced by 2.1- to 7.1-fold. Concentrations greater than $100 \mu \mathrm{M}$ were not tested, as they were observed to reduce the growth of $P$. syringae pv. tomato (Fig. 3B).

To determine whether intercellular SA accumulation during ARR plays a role in inhibiting biofilm formation in planta, a green fluorescent protein $(G F P)$-expressing strain of $P$. syringae pv. tomato DC3000 (carrying plasmid pDSK-GFPuv) (Wang et al. 2007) was used to monitor the formation of biofilm-like aggregates (groups of densely packed, stationary bacterial cells) in leaf tissue of young and mature Col-0 and svp-32 via fluorescence microscopy. Aggregates were not observed in leaves immediately after inoculation nor in the inoculum itself (Supplementary Fig. S6). At 24 hpi, aggregates and individual free-swimming (planktonic) bacterial cells were visible in the spaces between mesophyll cells with autofluorescent chloroplasts (Fig. 5A and B; Supplementary Fig. S7). For young Col-0 and svp mutants, most fields of view contained both

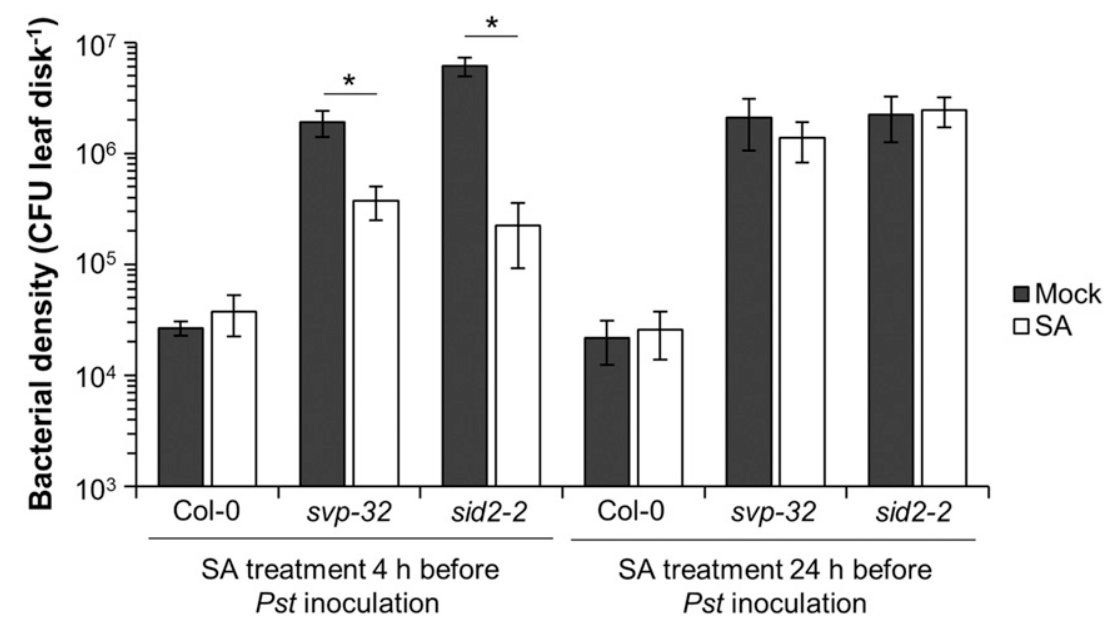

Fig. 2. Exogenous intercellular salicylic acid (SA) restores age-related resistance (ARR) to svp-32 mutants. Mature plants (7 weeks postgermination) were pressure-infiltrated with $0.1 \mathrm{mM} \mathrm{SA}$ or water (mock) either 4 or $24 \mathrm{~h}$ before inoculation with $10^{6} \mathrm{CFU} \mathrm{ml}^{-1}$ Pseudomonas syringae pv. tomato. Bacterial levels were quantified 3 days later. Each bar shows the mean of three sample replicates and error bars show the standard deviation. Asterisks indicate significant differences (analysis of variance, followed by Tukey's honestly significant difference test, $P<0.05$ ). This experiment was performed three times with similar results. 
free-swimming and aggregated cells (Fig. 5C). In contrast, most fields of view contained only free-swimming cells $(66 \%)$ for mature Col-0 leaves, whereas most fields of view for mature $s v p$ leaves contained both free-swimming and aggregated cells (77\%), similar to those for young plants. Taken together, these data support the hypothesis that mature, ARR-competent plants reduce the formation of biofilm-like aggregates through intercellular SA accumulation.

SA reduces growth and biofilm formation of $P$. syringae pv. tomato in a concentration-dependent manner in vitro. To gain insight into whether SA might function similarly in the intercellular space during ARR, it would be useful to know the concentration of SA in planta. While collection and examination of IWFs makes it possible to detect intercellular compounds, dilution of intercellular contents is a consequence of the collection procedure. To account for this, a dilution correction factor was calculated for mature Col-0 according to the indigo carmine method described by Husted and Schjoerring (1995). The dilution correction factor $(6.73 \pm 3.42$, average \pm standard deviation of three independent experiments) was applied to the concentrations of SA measured in IWFs and suggests that SA is present at 40 to $100 \mu \mathrm{M}$ in mature Col-0 at $24 \mathrm{hpi}$ with $P$. syringae pv. tomato. At these concentrations, SA has little effect on $P$. syringae pv.
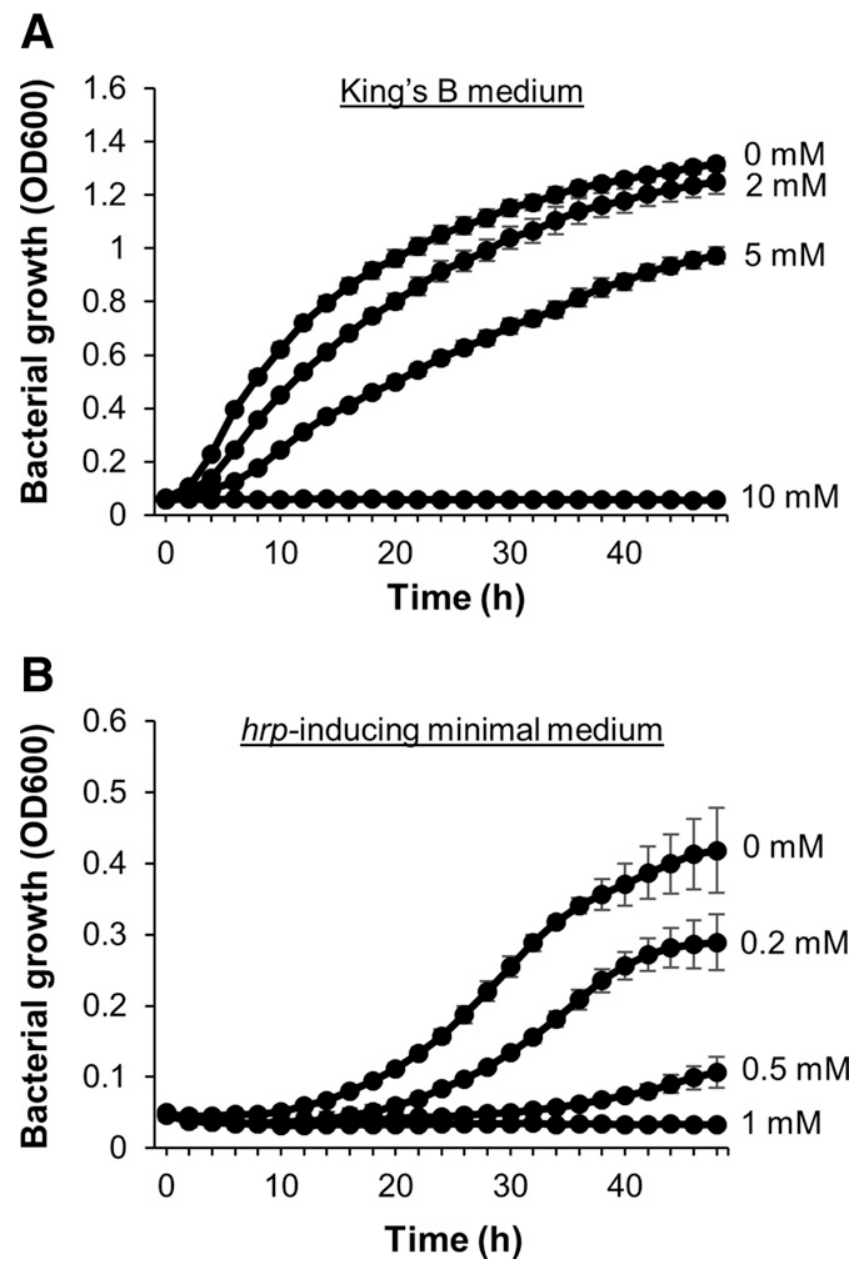

Fig. 3. Antibacterial activity of salicylic acid (SA) in vitro. A, Pseudomonas syringae pv. tomato was grown in King's B medium or B, hrpinducing minimal medium, along with the indicated concentrations of SA in a 96-well plate with shaking. Each data point shows the mean of four wells and error bars indicate standard deviation. These experiments were performed at least three times with similar results. tomato growth in vitro (Fig. 3B) but significantly reduces biofilm formation (Fig. 4).

\section{The ARR-defective phenotype of svp}

is not related to early flowering.

It is possible that morphological changes associated with early flowering contribute to the $s v p$ ARR defect. To examine this idea, KNAT1:SVP/svp-41 plants were assessed for ARR, since $S V P$ expression from the meristem-specific KNAT1 promoter delays flowering, while $S V P$ is nonfunctional in the leaves (Andrés et al. 2014). Col-0 did not flower during the experiment and showed a strong ARR response (119-fold reduction in bacterial levels in mature plants relative to young plants [Fig. 6]). The two KNAT1:SVP/svp-41 lines did not flower during the experiment and both lines displayed an ARR-defective phenotype similar to the $s v p-41$ parental line. Furthermore, this corresponded to reduced intercellular SA accumulation compared with wild type (Supplementary Fig. S8). Thus, the ARRdefective phenotype of $s v p$ mutants can be separated from early flowering, suggesting that the requirement of functional SVP for ARR is not an indirect effect of its role in flowering-time control.

Under long-day conditions, the onset of ARR is accelerated such that it occurs at 4 weeks postgermination (wpg) (Rusterucci et al. 2005). To determine whether SVP is required for ARR in long days, the KNAT1:SVP/svp-41 lines were used, since they flower later and produce more rosette leaves than $s v p-41$, making them more amenable to disease-resistance assays performed with long-day-grown plants. While Col-0 showed a 15-fold decrease in bacterial levels between 3 and 4 wpg, the KNATI: $S V P / s v p-41$ lines supported similarly high bacterial levels at 3 and 4 wpg (Supplementary Fig. S9). Therefore, meristemspecific expression of $S V P$ does not rescue the ARR defect of $s v p-41$ under long or short days, suggesting that functional SVP in leaves is required for the ARR response.

\section{SOC1 negatively influences ARR.}

SVP directly represses expression of SOC1 in both the meristem and leaves ( $\mathrm{Li}$ et al. 2008). To test whether SVP function during ARR is associated with its repression of SOC1, svp-32 soc1-2 double mutants were created and assayed for ARR. As shown previously (Wilson et al. 2013), soc1-2 single mutants display wild-type ARR (Fig. 7A). Interestingly, the svp-32 socl-2 double mutant was ARR-competent, indicating that SVP function is not required for ARR in a soc1-2 mutant background, and thus, the requirement of SVP for ARR may be due to its repression of $S O C 1$. This suggested that SOC1 may have a negative impact on $\mathrm{ARR}$, and indeed, the SOC1-overexpressing plant line soc $1-101 \mathrm{D}$ (Lee et al. 2000; Moon et al. 2005) was ARR defective and failed to accumulate intercellular SA (Fig. 7A and B). To further assess the potential involvement of SOC1 in ARR, transgenic plants with $\beta$-estradiol-inducible overexpression of $S O C 1$ were created (XVE:SOC1/soc1-2, discussed below). Maximum SOC1 expression levels were reached by $24 \mathrm{~h}$ after treatment with $\beta$-estradiol and were sustained for at least 3 days thereafter (Fig. 7E). To determine whether overexpression of SOCl impedes the ARR response, mature plants were pressure-infiltrated with $\beta$-estradiol or a mock solution $24 \mathrm{~h}$ before inoculation with $P$. syringae pv. tomato and bacterial levels were measured at $3 \mathrm{dpi}$. ARR was observed in the soc1-2 parental line and $\beta$-estradiol treatment had no effect on bacterial levels in socl-2. In contrast, two independent $X V E$ :SOC1/Soc $1-2$ lines consistently supported higher bacterial levels after $\beta$-estradiol treatment, although the difference was not always statistically significant (Fig. 7D). Together, these data suggest that SOC1 negatively impacts the ARR response downstream of SVP and upstream of intercellular SA accumulation. SOC1 was recently identified in a yeast one-hybrid screen for transcription factors that interact with the promoter of 
the SA biosynthesis gene ICS1 (Zheng et al. 2015). To test whether the negative impact of SOC 1 on ARR could be explained by repression of ICS1, expression of ICS1 was measured in mature Col-0 and soc1-101D plants before and after inoculation with $P$. syringae pv. tomato. While Col-0 displayed a 5.5-fold induction of ICSI expression at $24 \mathrm{hpi}$ with P. syringae pv. tomato, induction of ICS1 expression was not observed in soc 1-101D (Fig. 7C). Together, these data suggest that SOC1 negatively impacts ARR by repression of ICS1 expression and SA accumulation. A proposed model for the contribution of SVP and SOC1 to intercellular SA accumulation during ARR is presented in Figure 8.

Since soc1-101D plants also displayed enhanced susceptibility compared with wild type at the young-plant stage (Fig. 7A), XVE: $S O C 1 /$ soc 1-2 plants were used to further assess the possibility that SOC1 overexpression negatively impacts disease resistance in young plants. Young plants pressure-infiltrated with $\beta$-estradiol or a mock solution $24 \mathrm{~h}$ before inoculation with $P$. syringae $\mathrm{pv}$. tomato supported similar in-planta bacterial levels at 3 dpi (Supplementary Fig. S10), suggesting that $S O C 1$ overexpression has a greater impact on disease resistance in mature, compared with young, plants.

\section{DISCUSSION}

\section{SVP and SOC1 contribute to ARR.}

Consistent with the hypothesis that SVP regulates SA accumulation during ARR, the ARR-defective phenotype of svp mutants is associated with a reduced ability to accumulate intercellular free SA in response to $P$. syringae pv. tomato (threefold reduction relative to $\mathrm{Col}-0$ ). Moreover, exogenous SA applied to the intercellular space $4 \mathrm{~h}$ before pathogen inoculation restored ARR in svp mutants; however, no effect on ARR was observed when SA was applied $24 \mathrm{~h}$ before inoculation, since it has been demonstrated that SA is taken up by cells by $24 \mathrm{~h}$ after SA application (Cameron and Zaton 2004).

Since SVP directly represses SOC1 expression in seedlings (Gregis et al. 2013; Li et al. 2008), the ARR phenotype of $s v p-32$ soc1-2 mutants was tested to determine whether the function of SVP in ARR is associated with its repression of SOCl. The ARRcompetent phenotype of $s v p-32$ socl-2 mutants suggested that SOC1 acts downstream of SVP during ARR and that the requirement of SVP for ARR is related to its repression of SOC1. In support of this idea, constitutive $S O C l$ overexpressors were fully ARR-defective and failed to accumulate intercellular SA. $\beta$-estradiolinducible $S O C 1$ overexpression lines displayed a modest ARRdefective phenotype, which may be explained by higher SOC1 expression levels in constitutive overexpressors, as supported by the dose-dependent effect of SOCl on flowering time (Lee et al. 2000).

The negative impact of SOC1 on ARR appears to be due to repression of ICSI expression, since constitutive SOCI overexpressors are defective for pathogen-induced ICS1 expression and intercellular SA accumulation. Furthermore, repression of ICS1 expression by SOC1 may be direct, since SOC1 interacts with the ICS1 promoter in yeast one-hybrid experiments (Zheng et al. 2015). Young and mature wild-type plants express ICSI to similar levels in response to $P$. syringae pv. tomato (Rusterucci et al. 2005), suggesting that SVP and SOC1 do not regulate the onset of ARR competence in wild-type plants. Perhaps SOC1 only inhibits ARR when expressed at the high levels found in $s v p$ mutants or SOC1 overexpressors (Lee et al. 2000; Li et al. 2008).

The ARR-defective phenotype of $s v p$ mutants is not related to their early flowering phenotype, since KNAT1:SVP/svp-41 plants expressing functional $S V P$ only in the meristem did not
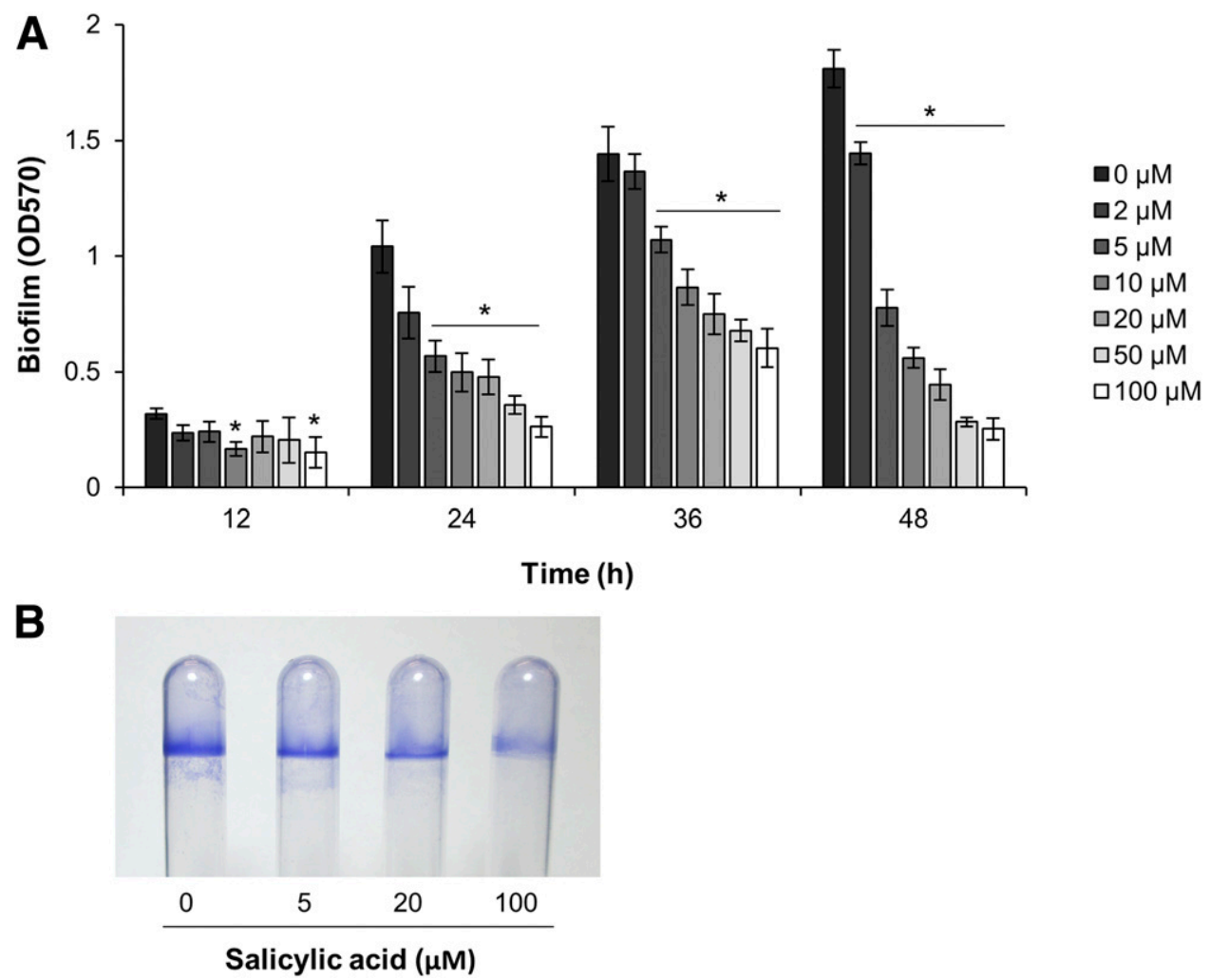

Fig. 4. Salicylic acid (SA) reduces biofilm formation in vitro. A, Pseudomonas syringae pv. tomato was cultured in hrp-inducing minimal medium along with the indicated concentration of SA at room temperature, without shaking, in a 96-well plate. At the indicated timepoints, plates were rinsed to remove unattached planktonic cells and biofilms were quantified by staining with crystal violet. Each bar shows the mean of four wells and error bars show standard deviation. Asterisks indicate significant differences relative to the $0-\mu \mathrm{M}$ control at the corresponding timepoint (analysis of variance, followed by Tukey's honestly significant difference test, $P<0.05)$. B, Similar assays were conducted in test tubes that were photographed after staining with crystal violet following $30 \mathrm{~h}$ of incubation. These experiments were performed three times with similar results. 
flower during short-day ARR experiments but remained ARRdefective. Similarly, the early flowering and ARR-defective phenotypes associated with constitutive SOC1 overexpression could be separated by inducible overexpression of SOCl during infection, which did not accelerate flowering but still negatively impacted ARR. Consistent with these results, the altered diseaseresistance phenotypes of several late-flowering mutants were unchanged by mutations or treatments that accelerated flowering (Lyons et al. 2015; Singh et al. 2013). Therefore, rather than the timing of flowering affecting disease resistance, some floweringtime regulators appear to have distinct effects on disease-resistance
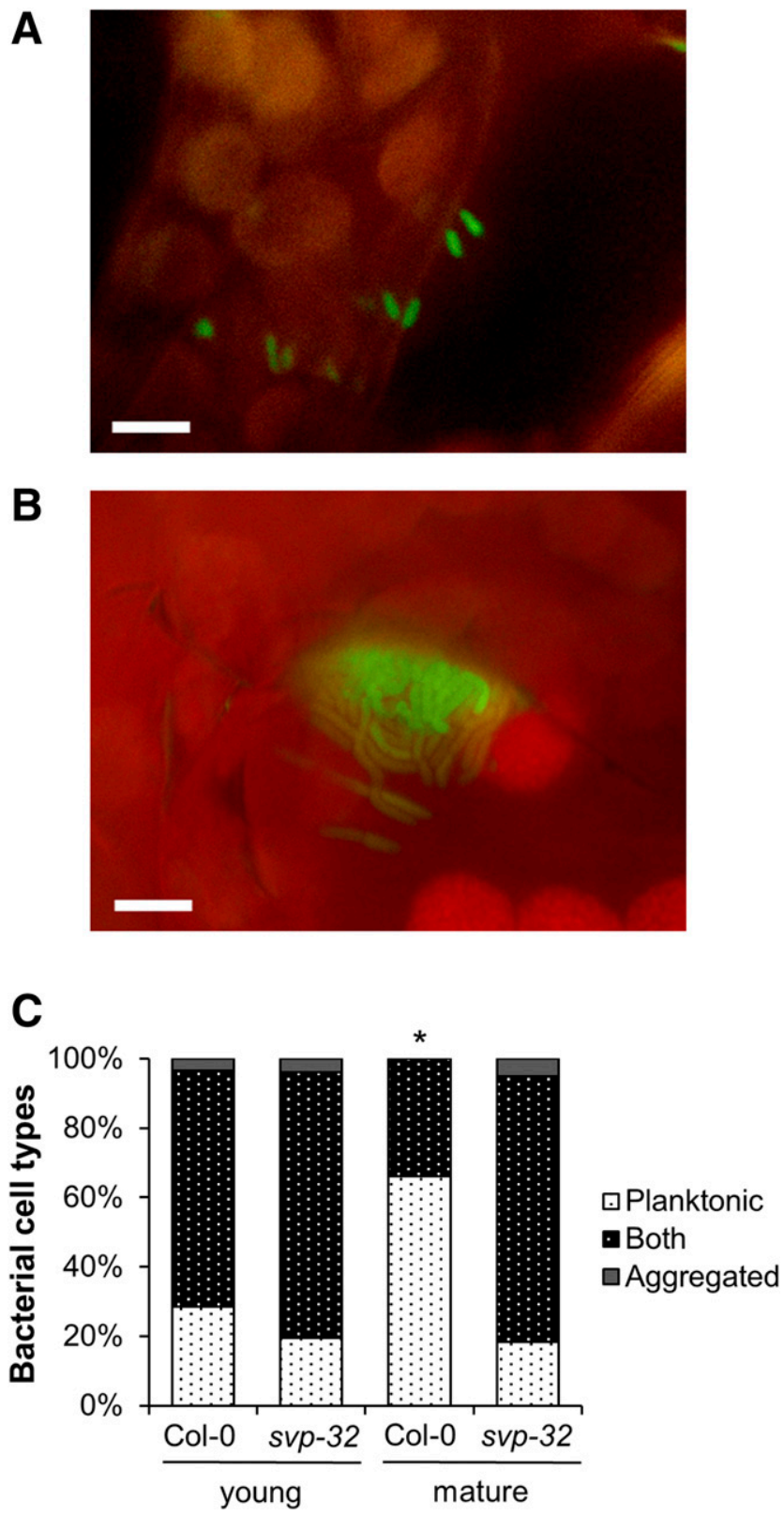

Fig. 5. Formation of bacterial aggregates in the leaf intercellular space. At $24 \mathrm{~h}$ after inoculation with $10^{6} \mathrm{CFU} \mathrm{ml}^{-1}$ of $P$. syringae pv. tomato carrying pDSKGFPuv, the lower epidermis was removed from the leaves and bacterial cells were imaged by epifluoresence microscopy. A, Individual, free-swimming (planktonic) cells and B, stationary aggregates were observed. $\mathbf{C}$, The proportion of bacterial cell types in plants of different ages (4 and 7 weeks postgermination) and genotypes was scored by assessing 8 to 10 fields of view from at least six plants for the presence of free-swimming cells, aggregated cells, or a mixture of both. The asterisk indicates a significant difference (Kruskal-Wallis test followed by Dunn's test). This experiment was performed three times with similar results. Scale bars $=5 \mu \mathrm{m}$. responses, such as systemic acquired resistance (FLD) (Singh et al. 2013), resistance to Fusarium oxysporum (FVE and FPA) (Lyons et al. 2015), and ARR (SVP and SOC1) (this work).

\section{Antibacterial activity of SA.}

Many studies have shown that SA exhibits antimicrobial activity against phytopathogens in vitro (Amborabé et al. 2002; Brown et al. 2007; Cameron and Zaton 2004; El-Mougy 2002; Georgiou et al. 2000; Martín et al. 2010; Prithiviraj et al. 1997; Lowe-Power et al. 2016; Yuan et al. 2007), with the range of effective concentrations spanning several orders of magnitude, probably due in large part to the different organisms and experimental conditions used. We found that SA displayed approximately 10 -fold greater antibacterial activity in minimal medium, which is a better representation of the conditions in the leaf intercellular space compared with rich media. This difference in SA antibacterial activity could be due to differential effects of these media on bacterial growth rate, physiology, and metabolism (Kim et al. 2010), or alternatively, on SA itself. For example, HIM medium has a $\mathrm{pH}$ of 5.7, similar to intercellular fluids (Jia and Davies 2007), whereas KB medium has a $\mathrm{pH}$ of 7.2. At lower $\mathrm{pH}$ levels, a greater proportion of SA exists in its protonated, lipophilic form, enhancing its ability to cross cell membranes, which may be a prerequisite for its antimicrobial activity. In support of this idea, Amborabé et al. (2002) showed that antifungal activity of SA against Eutypa lata increased

\begin{tabular}{lcccc}
\hline & & & \\
& Col-0 & \multicolumn{2}{c}{ KNAT1:SVP/svp-41 } & svp-41 \\
& & line 2 & line 5 & s. \\
\hline 2 wpg & 0 & 0 & 0 & 0 \\
3 wpg & 0 & 0 & 0 & 0 \\
$\mathbf{4}$ wpg & 0 & 0 & 0 & 32 \\
5 wpg & 0 & 0 & 0 & 91 \\
6 wpg & 0 & 0 & 0 & 100 \\
\hline
\end{tabular}

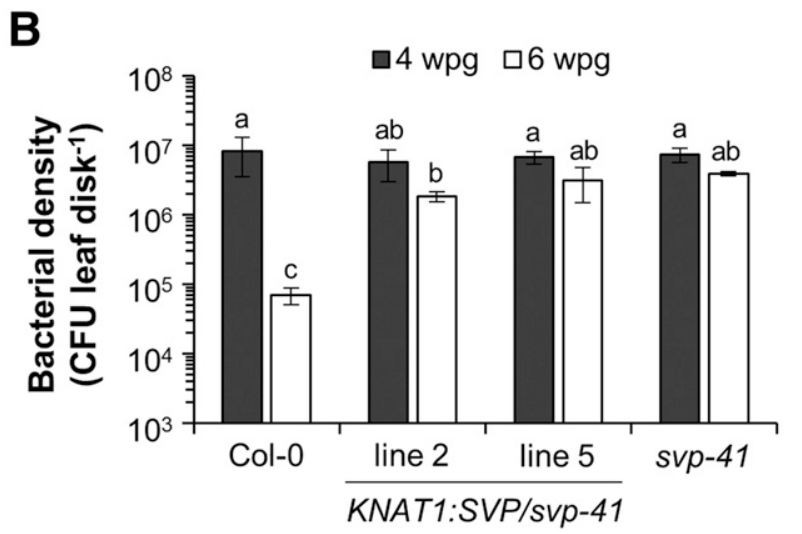

Fig. 6. The early flowering and age-related resistance (ARR)-defective phenotypes of $s v p-41$ are not linked. A, Percentage of plants with visible infloresence stems was scored each week starting at 2 weeks postgermination (wpg, $n \geq 9$ ). B, Plants were inoculated with $10^{6} \mathrm{CFU} \mathrm{ml^{-1 }}$ Pseudomonas syringae pv. tomato at either 4 or 6 wpg and bacterial levels were quantified 3 days later. Each bar shows the mean of three sample replicates and error bars show standard deviation. Different letters indicate significant differences (analysis of variance, followed by Tukey's honestly significant difference test, $P<0.05)$. This experiment was performed three times with similar results and was part of the experiment shown in Figure 1A. 
at lower $\mathrm{pH}$ levels and was associated with increased SA uptake by fungal hyphae. The mechanism of action of SA as an antimicrobial agent is not fully understood; however, several studies suggest that it may dissipate the transmembrane proton gradient required for ATP production (Gutknecht 1990; Jörgensen et al. 1976; Smith 1959;
Norman et al. 2004; Stenlid and Saddik 1962) or inhibit respiration (Norman et al. 2004) or catalase activity (Chen et al. 1993). In HIM medium, $P$. syringae pv. tomato growth was reduced at SA concentrations as low as 100 to $200 \mu \mathrm{M}$, suggesting that SA may be effective at similar concentrations in planta. Application of an

A

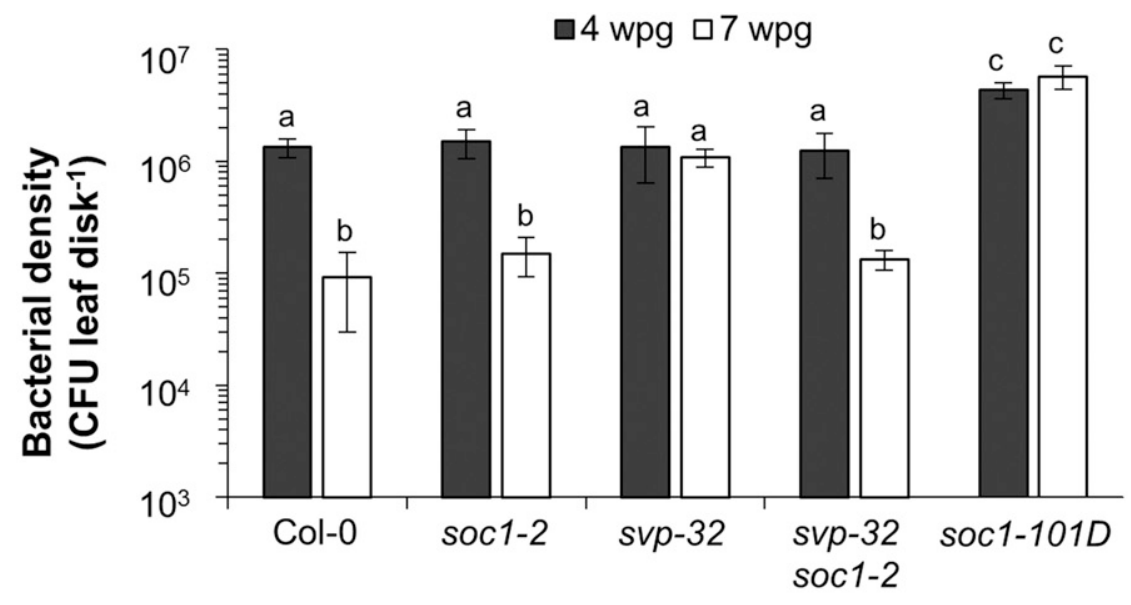

B

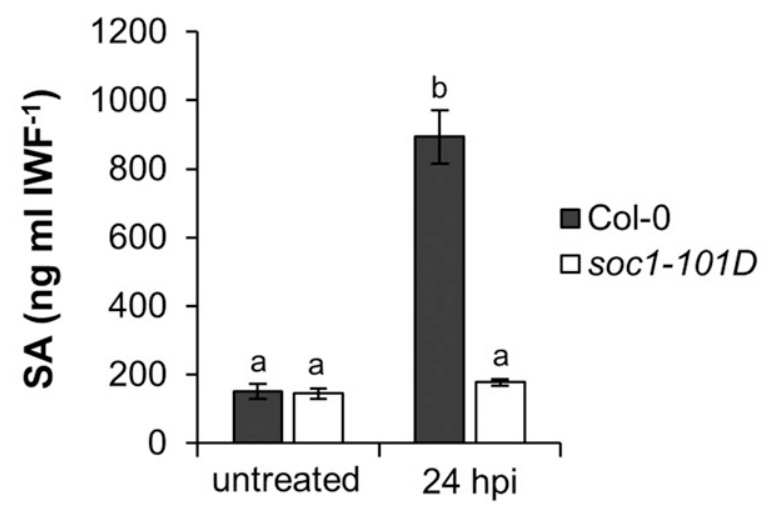

C

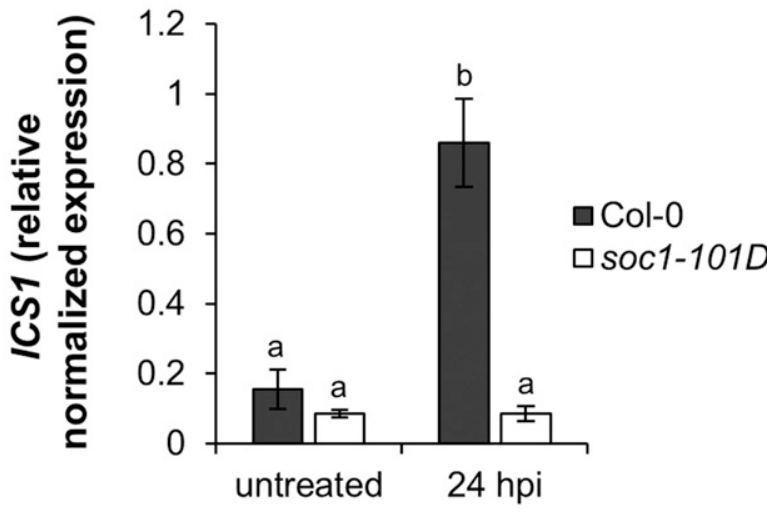

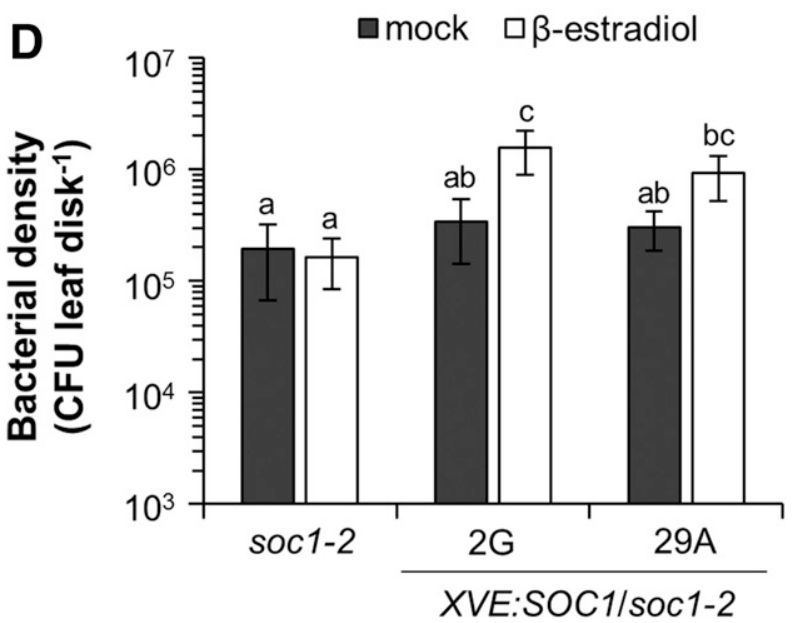

$\mathbf{E}$

\begin{tabular}{|c|c|c|c|c|c|c|c|c|}
\hline \multirow{2}{*}{$\beta$-estradiol } & \multicolumn{4}{|c|}{ line 2G } & \multicolumn{4}{|c|}{ line 29A } \\
\hline & - & - & + & + & - & - & + & + \\
\hline Time (h) & 24 & 96 & 24 & 96 & 24 & 96 & 24 & 96 \\
\hline SOC1 & & & & 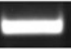 & & & $=$ & \\
\hline & & & & & & & & \\
\hline
\end{tabular}

Fig. 7. SOC1 negatively impacts age-related resistance (ARR). A, Plants were inoculated with $10^{6} \mathrm{CFU} \mathrm{ml} \mathrm{F}^{-1}$ Pseudomonas syringae pv. tomato at either 4 or 7 weeks postgermination (wpg) and bacterial levels were quantified 3 days later. Each bar shows the mean of three sample replicates and error bars show standard deviation. Different letters indicate significant differences (analysis of variance [ANOVA] followed by Tukey's honestly significant difference [HSD] test, $P<0.05$ ). B and C, Plants were inoculated with $10^{6} \mathrm{CFU} \mathrm{ml}{ }^{-1} P$. syringae pv. tomato at $6.5 \mathrm{wpg}$ and salicylic acid (SA) levels were quantified in intercellular washing fluids (B) and ICS1 expression was quantified in leaf tissue (C) collected from untreated or inoculated plants at $24 \mathrm{~h}$ postinoculation (hpi). D, Plants were pressure-infiltrated with $50 \mu \mathrm{M} \beta$-estradiol or a mock solution at $7 \mathrm{wpg}$ and were inoculated with a $10^{6} \mathrm{CFU} \mathrm{ml}^{-1}$ solution of $P$. syringae pv. tomato $24 \mathrm{~h}$ later. Bacterial levels were quantified 3 days after inoculation. Different letters indicate significant differences (ANOVA, followed by Tukey's HSD test, $P<0.05)$. E, SOC1 expression was measured by reverse transcription-polymerase chain reaction in leaf tissue of $X V E$ :SOC1/soc1-2 plants at 24 and 96 hpi with $50 \mu \mathrm{M} \beta$-estradiol (+) or a mock solution (-). These experiments were performed at least twice with similar results. 
experimentally determined dilution correction factor to SA levels measured in IWFs suggested that SA accumulates to 40 to $100 \mu \mathrm{M}$ in the intercellular space of mature plants $24 \mathrm{hpi}$ with $P$. syringae pv. tomato, similar to the levels that accumulate in the intercellular space of tobacco in response to Tobacco mosaic virus (Huang et al. 2006). These results suggest that SA may indeed act as an antimicrobial agent during ARR, especially given the possibility that SA is incompletely recovered during IWF collection and may also reach higher concentrations in microenvironments of the leaf intercellular space, which cannot be assessed using currently available techniques. Moreover, it is possible that other antimicrobials act together with SA during ARR.

\section{Biofilm formation by $P$. syringae and anti-biofilm activity of SA.}

Many $P$. syringae genes that are expressed in planta are also expressed in minimal but not rich media (Boch et al. 2002; Huynh et al. 1989; Rahme et al. 1992). Similarly, we found that $P$. syringae pv. tomato formed biofilms in intercellular spacemimicking minimal medium but not rich medium, leading to the idea that biofilm formation might also occur in planta. Indeed, fluorescence microscopy of leaves inoculated with GFPexpressing $P$. syringae pv. tomato revealed the presence of biofilmlike aggregates in the intercellular space at $24 \mathrm{hpi}$. Intriguingly, SA reduced $P$. syringae pv. tomato biofilm formation in vitro, at concentrations that were insufficient to affect growth and were estimated to exist in the intercellular space of mature wild-type plants. Furthermore, reduced formation of bacterial aggregates was observed in mature wild-type plants compared with young plants and mature $s v p$ mutants, both of which are impaired in intercellular SA accumulation. In young plants, $P$. syringae pv. tomato suppresses intercellular SA accumulation using the phytotoxin coronatine (Carviel et al. 2014), which contributes to bacterial growth and disease. On the other hand, mature ARR-competent plants accumulate intercellular SA in response
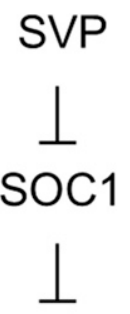

ICS1

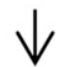

Intercellular

SA Accumulation

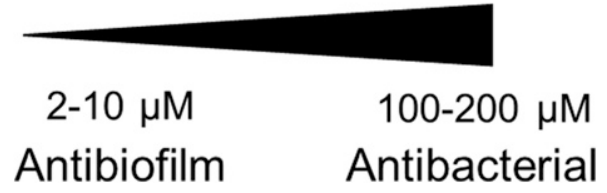

Fig. 8. Proposed model for the effect of SHORT VEGETATIVE PHASE (SVP) and SOC1 (SUPPRESSOR OF OVEREXPRESSION OF CO 1) on intercellular salicylic acid (SA) accumulation during age-related resistance (ARR). SVP is required for ARR to suppress the expression of SOC1, which codes for a MADS-domain transcription factor that negatively impacts ARR through repression of the SA biosynthesis gene ICS1. In the presence of functional SVP, mature plants accumulate intercellular SA, which limits either biofilm formation, bacterial growth, or both. to the same pathogen, leading us to speculate that ARRcompetent plants circumvent coronatine-mediated suppression of intercellular SA accumulation. Taken together, these data suggest that SA accumulation in the intercellular space reduces either $P$. syringae pv. tomato growth, biofilm formation, or both during ARR (Fig. 8).

Biofilms are usually described as surface-adherent aggregates of cells embedded in an extracellular matrix. These structures have been observed in several plant-pathogen interactions, are thought to provide protection against environmental stresses such as desiccation and antimicrobials, and have been linked to several virulence strategies (Danhorn and Fuqua 2007; Ichinose et al. 2013). In P. syringae, biofilms are largely studied in the context of epiphytic populations, although the kiwi pathogen $P$. syringae pv. actinidiae forms biofilms on both the leaf surface and within the intercellular space (Renzi et al. 2012). P. syringae pv. tomato biofilm formation is not well described; however, in leaves of Arabidopsis, $P$. syringae pv. tomato was shown to express algA and $\operatorname{alg} D$ (Boch et al. 2002; Keith et al. 2003), genes involved in the biosynthesis of alginate, the major extracellular polysaccharide produced by $P$. syringae pv. tomato in tomato (Fett and Dunn 1989). Intriguingly, $P$. syringae pv. tomato algD mutants exhibited reduced growth in Arabidopsis compared with wild-type $P$. syringae pv. tomato (approximately 10-fold) (Aslam et al. 2008), suggesting that biofilm formation contributes to $P$. syringae pv. tomato virulence.

Interestingly, SA treatment at concentrations that are insufficient to affect bacterial growth also reduce in vitro biofilm formation and virulence factor production in animal pathogens such as Pseudomonas aeruginosa and Staphylococcus aureus (Prithiviraj et al. 2005a and b; Yang et al. 2009). Similarly, in vitro SA treatment has been shown to suppress hrpA promoter activity in the plant pathogen Erwinia amylovora (Khokhani et al. 2013), the virA/G regulon of Agrobacterium tumefaciens (Yuan et al. 2007), and virulence gene expression in Ralstonia solanacearum (Lowe-Power et al. 2016). Yang et al. (2009) demonstrated that SA treatment interferes with multiple quorumsensing systems in $P$. aeruginosa. Furthermore, SA treatment activated the attKLM operon involved in degradation of quorumsensing signals in A. tumefaciens (Khokhani et al. 2013). Given that quorum sensing mediates many virulence strategies, including production of toxins, virulence effectors, and biofilm formation (Danhorn and Fuqua 2007; Ichinose et al. 2013), the ability of SA to suppress virulence in a wide range of pathogens may be due to an ability to interfere with quorum sensing. The in vivo and in vitro data presented in this paper provide evidence that SA acts directly on pathogens in planta; however, it is possible that SA also interacts with one or more host proteins that directly or indirectly influence bacterial survival or virulence.

Pathogens have evolved several strategies to resist the toxic effects of SA, including degradation of SA or its precursors (Tanaka et al. 2015). For example, $R$. solanacearum can degrade SA and use it as a carbon source (Lowe-Power et al. 2016). This ability confers enhanced SA tolerance in vitro and increased virulence on tobacco, compared with strains that cannot use SA as a carbon source (Lowe-Power et al. 2016). This ability does not appear to exist in P. syringae pv. tomato DC3000, which was unable to grow on SA as the sole carbon source.

Under biologically relevant conditions, SA concentrations in the micromolar range exhibit direct effects on pathogens, reducing their growth, virulence, or a combination of the two. We provide evidence that during ARR in Arabidopsis, SA accumulates in the intercellular space and contributes to suppression of $P$. syringae pv. tomato growth and biofilm formation. Furthermore, our data support the idea that the MADS-domain transcription factors SVP and SOC1 act antagonistically during flowering-time control and ARR, such that SVP is required for ARR to alleviate the negative 
impact of SOC1 on ICS1 expression and SA accumulation. A better understanding of the interplay between development and defense, as well as the mechanisms of action of compounds that reduce growth and virulence of pathogens, will be useful for optimizing crop performance in the future.

\section{MATERIALS AND METHODS}

\section{Plant lines and growth conditions.}

All plant lines used are in the Col-0 background and have been described previously: sid2-2 (Nawrath and Métraux 1999), svp32 (Lee et al. 2007), svp-41 (Hartmann et al. 2000), soc1-2 and soc1-101D (Lee et al. 2000), and KNAT1:SVP/svp-41 (Andrés et al. 2014). Initial experiments used the $s v p-32$ allele, but later experiments with KNAT1:SVP/svp-41 plants required that the svp-41 allele be used. Similar results were obtained with both alleles. The svp-32 soc1-2 mutant was created by crossing the corresponding single mutants. Seeds were surface-sterilized, were stratified for 2 days in darkness at $4^{\circ} \mathrm{C}$, and were then plated on Murashige and Skoog medium. Approximately 1 week later, cotyledon-stage seedlings were transplanted to soil (Sunshine Mix \#1) hydrated with $1 \mathrm{~g}$ of all-purpose 20-20-20 fertilizer per liter. Growth conditions were $22 \pm 2^{\circ} \mathrm{C}, 80 \% \pm 10 \%$ relative humidity, and $9 \mathrm{~h}$ of light, unless otherwise specified in the figure legend (mixed fluorescent and incandescent, 120 to $\left.150 \mu \mathrm{E} \mathrm{m}^{-1} \mathrm{~s}^{-1}\right)$.

To generate XVE:SOC1/soc1-2 the SOC1 coding sequence was polymerase chain reaction (PCR)-amplified from Col-0 cDNA, using primers 5'-TAAGCAGGCGCGCCATGGTGA GGGGCAAAACTC $(\mathrm{F})$ and 5'-TGCTTATTAATTAATCAC TTTCTTGAAGAACAAGGTAAC (R), and was cloned into the pER8 binary vector (Zuo et al. 2000) by restriction-ligation (AscI and SacI sites). The resulting construct was transformed into A. tumefaciens GV3101, soc1-2 mutants were transformed via the floral dip method (Clough and Bent 1998), and transformants were selected on the basis of hygromycin resistance $\left(25 \mu \mathrm{g} \mathrm{ml}^{-1}\right)$. $\beta$-estradiol (Sigma) was dissolved in dimethyl sulfoxide (DMSO), and a $50-\mu \mathrm{M}$ solution $(0.5 \%$ DMSO) was applied by pressure-infiltration with a needleless syringae.

\section{Disease resistance assays.}

Overnight cultures of $P$. syringae pv. tomato DC3000 were grown in $\mathrm{KB}$ medium to exponential phase. Cells were collected by centrifugation, were resuspended in $10 \mathrm{mM} \mathrm{MgCl}_{2}$ to $10^{6} \mathrm{CFU} \mathrm{ml}{ }^{-1}$, and were pressure-infiltrated into fully expanded leaves using a needleless syringe. For quantification of in-planta bacterial levels, three sets of eight leaf disks (4 mm diameter) were collected and shaken at $200 \mathrm{rpm}$ for $1 \mathrm{~h}$ in $10 \mathrm{mM} \mathrm{MgCl}_{2}$ with $0.1 \%$ Silwet L-77. Serial dilutions were plated on KB medium with kanamycin $\left(50 \mu \mathrm{g} \mathrm{ml}^{-1}\right)$ and rifampicin $\left(100 \mu \mathrm{g} \mathrm{ml}^{-1}\right)$, and colonies were counted 2 days later.

\section{IWF collection and \\ dilution correction factor determination.}

The technique for infiltration of leaves and collection of IWFs was adapted from Baker et al. (2012) and O'Leary et al. (2014). Three pools of eight to 12 leaves (or 30 to 40 leaves for soc1-101D plants, to account for their smaller size) were cut at the petiole and were vacuum-infiltrated with water inside a 60-ml syringe until they appeared completely water-soaked. Leaves were then blotted dry, were stacked between parafilm sheets, were rolled around a 1-ml pipette tip, were secured with a twist-tie, and were placed inside the bottom third of a $60-\mathrm{ml}$ syringe fitted to a $1.5-\mathrm{ml}$ centrifuge tube, with the petioles facing up. Leaves were then centrifuged using a swinging bucket rotor at $600 \times g$ for $15 \mathrm{~min}$ at room temperature, to collect the IWFs. In some cases, leaves were subsequently frozen in liquid nitrogen and were stored at $-80^{\circ} \mathrm{C}$ for SA quantification. IWFs were centrifuged for an additional $5 \mathrm{~min}$ at $13,000 \times \mathrm{g}$, were transferred to fresh tubes, were weighed, and were stored at $-80^{\circ} \mathrm{C}$. The remaining chlorophyll pellets (sometimes visible) were resuspended in $1 \mathrm{ml}$ of ethanol and were measured spectrophotometrically at 664 and $700 \mathrm{~nm}$, to assess contamination of IWFs with cellular contents (Baker et al. 2012). In a representative experiment, the chlorophyll levels in IWFs were $0.0085 \%$ of the corresponding leaf tissue, indicating that the IWFs had minimal cellular contamination.

The dilution correction factor was determined according to the method described by Husted and Schjoerring (1995), where dilution correction factor $=\left(\mathrm{V}_{\text {air }}+\mathrm{V}_{\text {water }}\right) / \mathrm{V}_{\text {water }}$ IWFs were collected as described above, except that leaves were vacuuminfiltrated with $50 \mu \mathrm{M}$ indigo carmine in $50 \mathrm{mM}$ sodium phosphate ( $\mathrm{pH}$ 6.2). The volume of intercellular air space $\left(\mathrm{V}_{\text {air }}\right)$ was estimated by calculating the difference in leaf weight before and after infiltration, and the volume of intercellular water $\left(\mathrm{V}_{\text {water }}\right)$ was calculated according to the equation $V_{\text {water }}=D_{\text {dye }} \times$ $\mathrm{V}_{\text {air }} /\left(1-\mathrm{D}_{\text {dye }}\right)$, where $\mathrm{D}_{\text {dye }}$ is the dilution of the dye after IWF collection. Indigo carmine was measured spectrophotometrically at $608 \mathrm{~nm}$.

\section{SA quantification.}

SA was quantified using the ADPWH_lux SA biosensor (DeFraia et al. 2008) as described previously (Carviel et al. 2014). Similar results were obtained when SA was quantified by gas chromatography-mass spectrometry (Supplementary Fig. S11).

\section{Antibacterial assays.}

For antibacterial assays with pure SA, overnight cultures of $P$. syringae pv. tomato $\mathrm{DC} 3000$ were grown in $\mathrm{KB}$ medium to exponential phase. Cells were collected by centrifugation, were washed twice with fresh $\mathrm{KB}$ ( $20 \mathrm{~g}$ of proteose peptone per liter, $10 \mathrm{ml}$ of glycerol per liter, $8.6 \mathrm{mM} \mathrm{K}_{2} \mathrm{HPO}_{4}, 6 \mathrm{mM} \mathrm{MgSO}_{4}$ ) or HIM (50 mM potassium phosphate buffer, $10 \mathrm{mM}$ fructose, $\left.7.6 \mathrm{mM}\left(\mathrm{NH}_{4}\right)_{2} \mathrm{SO}_{4}, 3.6 \mathrm{mM} \mathrm{MgCl}, 1.7 \mathrm{mM} \mathrm{NaCl}, \mathrm{pH} 5.7\right)$ medium, and were then resuspended in $\mathrm{KB}$ or HIM medium to an optical density at $600 \mathrm{~nm}$ of 0.05 . Aliquots of $160 \mu \mathrm{l}$ were added to a 96-well microplate (Corning) containing $3.2 \mu \mathrm{l}$ of SA (Sigma) or ethanol (the solvent used for SA stock solutions, $0.02 \%$ final concentration). Plates were incubated with shaking at room temperature in a Tecan Sunrise with absorbance $(600 \mathrm{~nm})$ measured every $15 \mathrm{~min}$. To determine bactericidal concentrations at the end of the experiment, well contents were transferred to microcentrifuge tubes and cells were collected by centrifugation, were resuspended in $10 \mathrm{mM} \mathrm{MgCl}_{2}$, and were then plated on $\mathrm{KB}$ medium with kanamycin $\left(50 \mu \mathrm{g} \mathrm{ml}^{-1}\right)$ and rifampicin $\left(100 \mu \mathrm{g} \mathrm{ml}^{-1}\right)$. Bactericidal activity was assumed if no growth was visible after at least 3 days.

\section{Biofilm assays.}

In vitro biofilm assays were performed essentially as described by O'Toole (2011). Overnight cultures of $P$. syringae pv. tomato DC3000 were grown to exponential phase in KB medium, were diluted with fresh KB or HIM medium (1:100), and 150- $\mu$ l aliquots were added to a 96-well microplate (Corning) containing SA or ethanol. The cultures were then incubated at room temperature and were stained at the indicated times. Prior to staining, microplates were inverted and were rinsed twice with water, to remove nonadherent cells. Each well was stained with $180 \mu \mathrm{l}$ of $0.1 \%$ crystal violet for $10 \mathrm{~min}$, followed by four washes with water to remove residual stain. For quantification of the stained biofilms, $200 \mu \mathrm{l}$ of $30 \%$ acetic acid was added to each well and was incubated for $15 \mathrm{~min}$, and then, absorbance was measured at $570 \mathrm{~nm}$. For qualitative assays, a similar procedure was followed, 
using a 500- $\mu$ l culture volume in polypropylene tubes that were photographed after the staining step.

\section{Imaging of $P$. syringae pv. tomato \\ in the intercellular space by epifluorescence microscopy.}

Plants were inoculated with a $10^{6} \mathrm{CFU} \mathrm{ml^{-1 }}$ solution of $P$. syringae pv. tomato carrying pDSK-GFPuv (Wang et al. 2007). After $24 \mathrm{~h}$, leaves were cut at the petiole and sections of the lower epidermis were removed using invisible tape. Sections without the lower epidermis were isolated using a razor blade and were mounted in water on a glass slide with coverslip with the epidermis-less surface facing upwards. Slides were imaged immediately, using a Nikon Eclipse E800 microscope fitted with a Nikon DS-Fil camera head and the DS-U3 control unit using $60 \times$ or $100 \times$ oil immersion lenses and a B-2A filter cube. For comparing the proportion of cell types between young and mature plants of different genotypes, tissue preparation and imaging were performed by different individuals so that the scoring was blind.

\section{Gene expression analysis.}

RNA extraction and cDNA synthesis were performed as described previously (Carviel et al. 2014), except that M-MLV reverse transcriptase (Sigma) was used. Quantitative reverse transcription (qRT)-PCR was performed using a BioRad CFX-96 Touch real-time PCR detection system with $20-\mu$ l reactions consisting of $2-\mu$ l template (cDNA diluted twofold with water), $400 \mathrm{nM}$ of each primer (annealing temperature $61^{\circ} \mathrm{C}$ ), and Advanced qPCR mastermix ( $1 \times$ final concentration; Wisent Bioproducts). For each sample, three biological replicates and two technical replicates were analyzed. Data analysis was performed using the BioRad CFX Manager 3.0 software, and CUL4 (AT5G46210) and SEC5A (AT1G76850) were used as reference genes. The identity of each qRT-PCR product was confirmed by sequencing. RT-PCR was performed using Taq DNA polymerase (ABM). Annealing temperatures and cycle numbers were $60^{\circ} \mathrm{C}$ and 28 cycles for ACTIN, and $53^{\circ} \mathrm{C}$ and 32 cycles for SOC1. Supplementary Table $\mathrm{S} 1$ lists the primers used.

\section{ACKNOWLEDGMENTS}

For sharing materials, we thank G. Coupland (KNAT1:SVP/svp-41), I. Lee (soc1-2 and soc1-101D), and K. Mysore (P. syringae pv. tomato pDSK-GFPuv).

\section{LITERATURE CITED}

Amasino, R. 2010. Seasonal and developmental timing of flowering. Plant J. 61:1001-1013

Amborabé, B., Fleurat-Lessard, P., Chollet, J., and Roblin, G. 2002. Antifungal effects of salicylic acid and other benzoic acid derivatives towards Eutypa lata: Structure-activity relationship. Plant Physiol. Biochem. 40:1051-1060.

Andrés, F., Porri, A., Torti, S., Mateos, J., Romera-Branchat, M., GarcíaMartínez, J. L., Fornara, F., Gregis, V., Kater, M. M., and Coupland, G. 2014. SHORT VEGETATIVE PHASE reduces gibberellin biosynthesis at the Arabidopsis shoot apex to regulate the floral transition. Proc. Natl. Acad. Sci. U.S.A. 111:E2760-E2769.

Aslam, S. N., Newman, M.-A., Erbs, G., Morrissey, K. L., Chinchilla, D., Boller, T., Jensen, T. T., De Castro, C., Ierano, T., Molinaro, A., Jackson, R. W., Knight, M. R., and Cooper, R. M. 2008. Bacterial polysaccharides suppress induced innate immunity by calcium chelation. Curr. Biol. 18:1078-1083.

Baker, J. C., Kovalskaya, N. Y., Mock, N. M., Owens, R. A., Deahl, K. L., Whitaker, B. D., Roberts, D. P., Hammond, R. W., and Aver'yanov, A. A. 2012. An internal standard technique for improved quantitative analysis of apoplastic metabolites in tomato leaves. Physiol. Mol. Plant Pathol. 78:31-37.

Boch, J., Joardar, V., Gao, L., Robertson, T. L., Lim, M., and Kunkel, B. N. 2002. Identification of Pseudomonas syringae pv. tomato genes induced during infection of Arabidopsis thaliana. Mol. Microbiol. 44:73-88.

Brown, D. G., Swanson, J. K., and Allen, C. 2007. Two host-induced Ralstonia solanacearum genes, acrA and $\operatorname{din} F$, encode multidrug efflux pumps and contribute to bacterial wilt virulence. Appl. Environ. Microbiol. 73:2777-2786.

Cameron, R. K., and Zaton, K. 2004. Intercellular salicylic acid accumulation is important for age-related resistance in Arabidopsis to Pseudomonas syringae. Physiol. Mol. Plant Pathol. 65:197-209.

Carella, P., Wilson, D. C., and Cameron, R. K. 2015. Some things get better with age: Differences in salicylic acid accumulation and defense signaling in young and mature Arabidopsis. Front. Plant Sci. 5:775.

Carviel, J. L., Al-Daoud, F., Neumann, M., Mohammad, A., Provart, N. J., Moeder, W., Yoshioka, K., and Cameron, R. K. 2009. Forward and reverse genetics to identify genes involved in the age-related resistance response in Arabidopsis thaliana. Mol. Plant Pathol. 10:621-634.

Carviel, J. L., Wilson, D. C., Isaacs, M., Carella, P., Catana, V., Golding, B., Weretilnyk, E. A., and Cameron, R. K. 2014. Investigation of intercellular salicylic acid accumulation during compatible and incompatible Arabidopsispseudomonas syringae interactions using a fast neutron-generated mutant allele of EDS5 identified by genetic mapping and whole-genome sequencing. PLoS One 9:e88608.

Chen, Z., Silva, H., and Klessig, D. F. 1993. Active oxygen species in the induction of plant systemic acquired resistance by salicylic acid. Science 262:1883-1886.

Clough, S. J., and Bent, A. F. 1998. Floral dip: A simplified method for Agrobacterium-mediated transformation of Arabidopsis thaliana. Plant $\mathrm{J}$. 16:735-743.

Danhorn, T., and Fuqua, C. 2007. Biofilm formation by plant-associated bacteria. Annu. Rev. Microbiol. 61:401-422.

DeFraia, C. T., Schmelz, E. A., and Mou, Z. 2008. A rapid biosensor-based method for quantification of free and glucose-conjugated salicylic acid. Plant Methods 4:28.

Develey-Rivière, M.-P., and Galiana, E. 2007. Resistance to pathogens and host developmental stage: A multifaceted relationship within the plant kingdom. New Phytol. 175:405-416.

El-Mougy, N. S. 2002. In vitro studies on antimicrobial activity of salicylic acid and acetyl salicylic acid as pesticidal alternatives against some soilborne plant pathogens. Egypt. J. Phytopathol. 30:41-55.

Fett, W. F., and Dunn, M. F. 1989. Exopolysaccharides produced by phytopathogenic Pseudomonas syringae pathovars in infected leaves of susceptible hosts. Plant Physiol. 89:5-9.

Fornara, F., de Montaigu, A., Coupland, G. 2010. SnapShot: Control of flowering in Arabidopsis. Cell 141:550-550e.2.

Georgiou, C. D., Tairis, N., and Sotiropoulou, A. 2000. Hydroxyl radical scavengers inhibit lateral-type sclerotial differentiation and growth in phytopathogenic fungi. Mycologia 92:825-834.

Gregis, V., Andrés, F., Sessa, A., Guerra, R. F., Simonini, S., Mateos, J. L., Torti, S., Zambelli, F., Prazzoli, G. M., Bjerkan, K. N., Grini, P. E., Pavesi, G., Colombo, L., Coupland, G., and Kater, M. M. 2013. Identification of pathways directly regulated by SHORT VEGETATIVE PHASE during vegetative and reproductive development in Arabidopsis. Genome Biol. 14:R56.

Gutknecht, J. 1990. Salicylates and proton transport through lipid bilayer membranes: A model for salicylate-induced uncoupling and swelling in mitochondria. J. Membr. Biol. 115:253-260.

Hartmann, U., Höhmann, S., Nettesheim, K., Wisman, E., Saedler, H., and Huijser, P. 2000. Molecular cloning of SVP: a negative regulator of the floral transition in Arabidopsis. Plant J. 21:351-360.

Huang, W. E., Huang, L., Preston, G. M., Naylor, M., Carr, J. P., Li, Y., Singer, A. C., Whiteley, A. S., and Wang, H. 2006. Quantitative in situ assay of salicylic acid in tobacco leaves using a genetically modified biosensor strain of Acinetobacter sp. ADP1. Plant J. 46:1073-1083.

Husted, S., and Schjoerring, J. K. 1995. Apoplastic pH and ammonium concentration in leaves of Brassica napus L. Plant Physiol. 109:1453-1460.

Huynh, T. V., Dahlbeck, D., and Staskawicz, B. J. 1989. Bacterial blight of soybean: Regulation of a pathogen gene determining host cultivar specificity. Science 245:1374-1377.

Ichinose, Y., Taguchi, F., and Mukaihara, T. 2013. Pathogenicity and virulence factors of Pseudomonas syringae. J. Gen. Plant Pathol. 79 285-296.

Jia, W., and Davies, W. J. 2007. Modification of leaf apoplastic pH in relation to stomatal sensitivity to root-sourced abscisic acid signals Plant Physiol. 143:68-77.

Jörgensen, T. G., Weis-Fogh, U. S., Nielsen, H. H., and Olesen, H. P. 1976. Salicylate- and aspirin-induced uncoupling of oxidative phosphorylation in mitochondria isolated from the mucosal membrane of the stomach. Scand. J. Clin. Lab. Invest. 36:649-654.

Keith, R. C., Keith, L. M. W., Hernández-Guzmán, G., Uppalapati, S. R., and Bender, C. L. 2003. Alginate gene expression by Pseudomonas syringae pv. tomato DC3000 in host and non-host plants. Microbiology 149:1127-1138. 
Khokhani, D., Zhang, C., Li, Y., Wang, Q., Zeng, Q., Yamazaki, A., Hutchins, W., Zhou, S.-S., Chen, X., and Yang, C.-H. 2013. Discovery of plant phenolic compounds that act as type III secretion system inhibitors or inducers of the fire blight pathogen, Erwinia amylovora. Appl. Environ. Microbiol. 79:5424-5436.

Kim, B. J., Schneider, D. J., Cartinhour, S. W., and Shuler, M. L. 2010. Complex responses to culture conditions in Pseudomonas syringae pv. tomato DC3000 continuous cultures: The role of iron in cell growth and virulence factor induction. Biotechnol. Bioeng. 105:955-964.

Kus, J. V., Zaton, K., Sarkar, R., and Cameron, R. K. 2002. Age-related resistance in Arabidopsis is a developmentally regulated defense response to Pseudomonas syringae. Plant Cell 14:479-490.

Lee, H., Suh, S.-S., Park, E., Cho, E., Ahn, J. H., Kim, S.-G., Lee, J. S., Kwon, Y. M., and Lee, I. 2000. The AGAMOUS-LIKE 20 MADS domain protein integrates floral inductive pathways in Arabidopsis. Genes Dev. 14:2366-2376.

Lee, J., Oh, M., Park, H., and Lee, I. 2008. SOC1 translocated to the nucleus by interaction with AGL24 directly regulates leafy. Plant J. 55:832-843.

Lee, J. H., Yoo, S. J., Park, S. H., Hwang, I., Lee, J. S., and Ahn, J. H. 2007. Role of SVP in the control of flowering time by ambient temperature in Arabidopsis. Genes Dev. 21:397-402.

Li, D., Liu, C., Shen, L., Wu, Y., Chen, H., Robertson, M., Helliwell, C. A., Ito, T., Meyerowitz, E., and Yu, H. 2008. A repressor complex governs the integration of flowering signals in Arabidopsis. Dev. Cell 15:110-120.

Liu, C., Chen, H., Er, H. L., Soo, H. M., Kumar, P. P., Han, J.-H., Liou, Y. C., and Yu, H. 2008. Direct interaction of AGL24 and SOC1 integrates flowering signals in Arabidopsis. Development 135:1481-1491.

Lowe-Power, T. M., Jacobs, J. M., Ailloud, F., Fochs, B., Prior, P., and Allen, C. 2016. Degradation of the plant defense signal salicylic acid protects Ralstonia solanacearum from toxicity and enhances virulence on tobacco. MBio 7:e00656-16.

Lyons, R., Rusu, A., Stiller, J., Powell, J., Manners, J. M., and Kazan, K. 2015. Investigating the association between flowering time and defense in the Arabidopsis thaliana-Fusarium oxysporum interaction. PLoS One 10:e0127699.

Martín, J. A., Solla, A., Witzell, J., Gil, L., and García-Vallejo, M. C. 2010. Antifungal effect and reduction of Ulmus minor symptoms to Ophiostoma novo-ulmi by carvacrol and salicylic acid. Eur. J. Plant Pathol. 127:21-32.

Moon, J., Lee, H., Kim, M., and Lee, I. 2005. Analysis of flowering pathway integrators in Arabidopsis. Plant Cell Physiol. 46:292-299.

Nawrath, C., and Métraux, J.-P. 1999. Salicylic acid induction-deficient mutants of Arabidopsis express $P R-2$ and $P R-5$ and accumulate high levels of camalexin after pathogen inoculation. Plant Cell 11:1393-1404.

Norman, C., Howell, K. A., Millar, A. H., Whelan, J. M., and Day, D. A. 2004. Salicylic acid is an uncoupler and inhibitor of mitochondrial electron transport. Plant Physiol. 134:492-501

O’Leary, B. M., Rico, A., McCraw, S., Fones, H. N., and Preston, G. M. 2014. The infiltration-centrifugation technique for extraction of apoplastic fluid from plant leaves using Phaseolus vulgaris as an example. J. Vis. Exp. 94:e52113.

O'Toole, G. A. 2011. Microtiter dish biofilm formation assay. J. Vis. Exp. 47:2437.

Prithiviraj, B., Manickam, M., Singh, U. P., Ray, A. B. 1997. Antifungal activity of anacardic acid a naturally occurring derivative of salicylic acid. Can. J. Bot. 75:207-211.

Prithiviraj, B., Bais, H. P., Jha, A. K., and Vivanco, J. M. 2005a. Staphylococcus aureus pathogenicity on Arabidopsis thaliana is mediated either by a direct effect of salicylic acid on the pathogen or by SAdependent, NPR1-independent host responses. Plant J. 42:417-432.

Prithiviraj, B., Bais, H. P., Weir, T., Suresh, B., Najarro, E. H., Dayakar, B. V., Schweizer, H. P., and Vivanco, J. M. 2005b. Down regulation of virulence factors of Pseudomonas aeruginosa by salicylic acid attenuates its virulence on Arabidopsis thaliana and Caenorhabditis elegans. Infect. Immun. 73: 5319-5328.
Rabe, F., Ajami-Rashidi, Z., Doehlemann, G., Kahmann, R., and Djamei, A. 2013. Degradation of the plant defence hormone salicylic acid by the biotrophic fungus Ustilago maydis. Mol. Microbiol. 89:179-188.

Rahme, L. G., Mindrinos, M. N., and Panopoulos, N. J. 1992. Plant and environmental sensory signals control the expression of hrp genes in Pseudomonas syringae pv. phaseolicola. J. Bacteriol. 174:3499-3507.

Renzi, M., Copini, P., Taddei, A. R., Rossetti, A., Gallipoli, L., Mazzaglia, A., and Balestra, G. M. 2012. Bacterial canker on kiwifruit in Italy: Anatomical changes in the wood and in the primary infection sites. Phytopathology 102:827-840.

Rusterucci, C., Zhao, Z., Haines, K., Mellersh, D., Neumann, M., and Cameron, R. K. 2005. Age-related resistance to Pseudomonas syringae pv. tomato is associated with the transition to flowering in Arabidopsis and is effective against Peronospora parasitica. Physiol. Mol. Plant Pathol. 66:222-231.

Schenk, A., Weingart, H., and Ullrich, M. S. 2008. The alternative sigma factor AlgT, but not alginate synthesis, promotes in planta multiplication of Pseudomonas syringae pv. glycinea. Microbiology 154:413-421.

Singh, V., Roy, S., Giri, M. K., Chaturvedi, R., Chowdhury, Z., Shah, J., and Nandi, A. K. 2013. Arabidopsis thaliana FLOWERING LOCUS D is required for systemic acquired resistance. Mol. Plant-Microbe Interact 26:1079-1088.

Smith, M. J. H. 1959. Salicylates and metabolism. J. Pharm. Pharmacol. 11: 705-720.

Stenlid, G., and Saddik, K. 1962. The effect of some growth regulators and uncoupling agents upon oxidative phosphorylation in mitochondria of cucumber hypocotyls. Physiol. Plant. 15:369-379.

Tanaka, S., Han, X., and Kahmann, R. 2015. Microbial effectors target multiple steps in the salicylic acid production and signaling pathway. Front. Plant Sci. 6:349.

Van Duy, N, Mäder, U., Tran, N. P., Cavin, J.-F., Tam, T., Albrecht, D., Hecker, M., and Antelmann, H. 2007. The proteome and transcriptome analysis of Bacillus subtilis in response to salicylic acid. Proteomics 7:698-710.

Wang, K., Kang, L., Anand, A., Lazarovits, G., and Mysore, K. S. 2007. Monitoring in planta bacterial infection at both cellular and whole-plant levels using the green fluorescent protein variant GFPuv. New Phytol. 174:212-223

Whalen, M. C. 2005. Host defence in a developmental context. Mol. Plant Pathol. 6:347-360.

Wilson, D. C., Carella, P., Isaacs, M., and Cameron, R. K. 2013. The floral transition is not the developmental switch that confers competence for the Arabidopsis age-related resistance response to Pseudomonas syringae pv. tomato. Plant Mol. Biol. 83:235-246.

Yang, L., Rybtke, M. T., Jakobsen, T. H., Hentzer, M., Bjarnsholt, T., Givskov, M., and Tolker-Nielsen, T. 2009. Computer-aided identification of recognized drugs as Pseudomonas aeruginosa quorum-sensing inhibitors. Antimicrob. Agents Chemother. 53:2432-2443.

Yu, J., Peñaloza-Vázquez, A., Chakrabarty, A. M., and Bender, C. L. 1999. Involvement of the exopolysaccharide alginate in the virulence and epiphytic fitness of Pseudomonas syringae pv. syringae. Mol. Microbiol. 33:712-720.

Yuan, Z.-C., Edlind, M. P., Liu, P., Saenkham, P., Banta, L. M., Wise, A. A., Ronzone, E., Binns, A. N., Kerr, K., and Nester, E. W. 2007. The plant signal salicylic acid shuts down expression of the vir regulon and activates quormone-quenching genes in Agrobacterium. Proc. Natl. Acad. Sci. U.S.A. 104:11790-11795.

Zheng, X.-Y., Zhou, M., Yoo, H., Pruneda-Paz, J. L., Spivey, N. W., Kay, S. A., and Dong, X. 2015. Spatial and temporal regulation of biosynthesis of the plant immune signal salicylic acid. Proc. Natl. Acad. Sci. U.S.A. 112:9166-9173.

Zuo, J., Niu, Q.-W., and Chua, N.-H. 2000. An estrogen receptor-based transactivator XVE mediates highly inducible gene expression in transgenic plants. Plant J. 24:265-273. 